\title{
Smoking cessation improves both direct and indirect airway hyperresponsiveness in COPD
}

\author{
B.W.M. Willemse*,\#, N.H.T. ten Hacken", B. Rutgers*, I.G.A.T. Lesman-Leegte ${ }^{\#}$, W. Timens*, \\ D.S. Postma ${ }^{\prime \prime}$
}

Smoking cessation improves both direct and indirect airway hyperresponsiveness in COPD. B. W.M. Willemse, N.H.T. ten Hacken, B. Rutgers, I.G.A.T. Lesman-Leegte, W. Timens, D.S. Postma. (C) ERS Journals Ltd 2004.

ABSTRACT: Smoking induces chronic obstructive pulmonary disease (COPD) and is associated with airway inflammation and airway hyperresponsiveness (AHR). It has not been studied in COPD whether direct (methacholine) and indirect (adenosine-5'monophosphate (AMP)) stimuli are associated with airway inflammation and neither whether smoking cessation improves these features.

The current authors cross-sectionally investigated the relationship of AHR to methacholine and AMP with lung function and inflammatory cells in the sputum of 33 smokers with COPD. In addition, changes in these parameters were prospectively assessed in 14 smokers who successfully quit smoking for $1 \mathrm{yr}$.

The presence of AHR to both methacholine and AMP was associated with lower lung function, but not with sputum inflammation. AHR to methacholine and AMP improved significantly after a 1-yr smoking cessation, yet this was unrelated to changes in sputum cell counts. The numbers of neutrophils and epithelial cells significantly increased with smoking cessation.

Both direct and indirect airway hyperresponsiveness are associated with lower lung function, but not with sputum inflammation in chronic obstructive pulmonary disease. Interestingly, 1-yr smoking cessation improved both direct and indirect airway hyperresponsiveness, yet without a significant association with changes in lung function or sputum inflammation. Thus, other factors are likely to induce these improvements, e.g. a reduction in stimulation of irritant receptors, airway wall changes or mucus hypersecretion.

Eur Respir J 2004; 24: 391-396.
Depts of *Pathology and ${ }^{*}$ Pulmonology, University Hospital Groningen, Groningen, the Netherlands.

Correspondence: B. Willemse, University Hospital Groningen, Dept of Pathology, Hanzeplein 1, 9713 GZ Groningen, the Netherlands.

Fax: 310503632510

E-mail: b.w.m.willemse@path.azg.nl

Keywords: Adenosine-5'-monophosphate airway hyperresponsiveness

chronic obstructive pulmonary disease methacholine

smoking cessation

sputum inflammation

Received: March 122003

Accepted after revision: April 162004

This research was supported by the Netherlands Asthma Foundation (AF 32.97.74).
It is now widely accepted that airway hyperresponsiveness (AHR) may occur both in asthma and chronic obstructive pulmonary disease (COPD) [1-3]. It is clear that smoking induces COPD, but it may also contribute to AHR by the induction of airway inflammation and by geometric changes of the airways due to airway smooth muscle hypertrophy, mucus hypersecretion and loss of alveolar attachments [4-8]. Smoking cessation is the only measure to prevent accelerated loss of lung function [9, 10]. Given the observed association between smoking and AHR, it may be anticipated that smoking cessation also improves AHR in COPD.

AHR can be measured using direct and indirect stimuli as provocative substances. Histamine and methacholine act directly on airway smooth muscle cells via binding to histamine and muscarinic receptors, respectively. Adenosine$5^{\prime}$-monophosphate (AMP) is a stimulus that acts indirectly on smooth muscle cells via activation of inflammatory cells, especially mast cells, or via neural pathways [11]. Only a few studies have investigated the effect of smoking on AHR in COPD patients. Two cross-sectional studies showed no differences in AHR to histamine or methacholine between exsmokers and smokers with COPD $[12,13]$. In contrast, the Lung Health Study showed that AHR to methacholine deteriorated to a smaller extend in quitters than in persistent smokers [14]. OOSTERHOFF et al. [13] reported that exsmokers with COPD were less hyperresponsive to AMP than smokers with mild COPD, despite the fact that they had similar levels of methacholine responsiveness. This suggests that smoking affects AMP responsiveness in particular.

In asthma, AMP responsiveness reflects airway inflammation more closely than methacholine responsiveness $[15,16]$. In COPD, increased methacholine responsiveness has been associated with more extensive airway inflammation in lung tissue and a higher number of T-lymphocytes [6, 17]. In exsmoking COPD patients, more severe AMP responsiveness was associated with an increased percentage of sputum eosinophils and CD8+ lymphocytes in bronchial biopsies [18].

In this study, the current authors evaluated 33 smokers with COPD in order to investigate the relationship of methacholine and AMP responsiveness with lung function and sputum inflammatory indices. The current authors subsequently assessed the effect of a 1-yr successful smoking cessation on both the provocative concentration causing a $20 \%$ fall in forced expiratory volume in one second (PC20) of methacholine and AMP and the associated changes in lung function and sputum inflammatory indices in 15 patients of this group.

\section{Methods}

\section{Patients}

Smokers with COPD were included according to European Respiratory Society criteria [19], e.g. chronic cough and 
sputum production for $\geqslant 3$ months for 2 successive yrs, forced expiratory volume in one second (FEV1)/vital capacity (VC) $<88 \%$ predicted for males and $<89 \%$ pred for females. In addition, subjects met the following criteria: 1) reversibility to salbutamol $<9 \%$ of the predicted FEV1;2) no use of inhaled or oral corticosteroids at entry and in the previous 6 months; and 3) no atopy (no positive skin-prick test for 10 common aeroallergens, serum total immunoglobulin $\mathrm{E}<200 \mathrm{IU})$. During the study, patients only used long-acting or shortacting $\beta_{2}$-agonist or ipratropium on regular basis; no inhaled corticosteroids were used. Only in the case of exacerbation was a short course of oral corticosteroids used. Patients were recruited from the pulmonary outpatient clinic of the Groningen University Hospital, Groningen, The Netherlands, and by advertisements in local newspapers. The local medical ethics committee approved the study protocol. All patients gave their written informed consent.

\section{Study design}

All patients visited the hospital on 4 days, at least 1 week apart, before entry into a 1-yr smoking cessation behavioural programme. AHR to methacholine and AMP were performed and this was repeated in patients who successfully quit smoking for $1 \mathrm{yr}$. Sputum induction was performed before and after 2, 6 and 12 months smoking cessation. In order to investigate the repeatability of sputum cells, sputum induction was performed twice before entry into the smoking-cessation programme. Before each measurement, subjects were asked not to use long- or short-acting $\beta_{2}$-agonist and/or ipratropium $\geqslant 12 \mathrm{~h}$ before the test. The subjects did not suffer from a respiratory tract infection nor used oral corticosteroids in the month prior to the measurement.

The smoking cessation behavioural programme consisted of an intensive group-orientated course for 3 months, followed by five meetings throughout the rest of the year. If necessary, nicotine replacements were administered during the first 3 months; no bupropion or antidepressants were prescribed. Measuring cotinine levels in urine verified smoking cessation before, 2, 6 and 12 months after smoking cessation. A quitter was defined as someone who refrained from smoking for $\geqslant 1 \mathrm{yr}$, with negative cotinine levels at 2, 6 and 12 months after smoking cessation.

\section{Airway function}

Lung function (FEV1, FEV1/VC) was measured using dry-wedge spirometry (Masterscope; Jaeger, Breda, The Netherlands) according to standardised guidelines [20]. Airway conductance ( $\mathrm{s} G \mathrm{aw}$ ) was measured by body plethysmography (Masterscope; Jaeger). Provocation tests were performed with a 2-min tidal breathing method adapted from COCKCROFT et al. [21]. After an initial nebulised saline challenge, subjects inhaled doubling concentrations, ranging from 0.038 $39.2 \mathrm{mg} \cdot \mathrm{mL}^{-1}$ of methacholine-bromide (Sigma Chemical Co., St Louis, MO, USA) and $0.04-320 \mathrm{mg} \cdot \mathrm{mL}^{-1}$ of AMP (Sigma Chemical Co.), at 5-min intervals. The test was terminated when PC20 was reached.

\section{Sputum induction and sputum processing}

Sputum was induced by inhalation of hypertonic saline aerosol as described previously [22]. Hypertonic saline $(3 \%$, $4 \%$ and $5 \% \mathrm{w} / \mathrm{v}$ ) was nebulised for each concentration over a period of $7 \mathrm{~min}, 15 \mathrm{~min}$ after salbutamol $(400 \mu \mathrm{g})$ inhalation.
Whole sputum samples were processed according to the methods of RUTGERS et al. [22] and FAHY et al. [23] with some modifications. Sputum cytospin slides were stained with MayGrünwald-Giemsa for differential cell counts.

\section{Data analysis}

All calculations of PC20 were made with the base-2 logarithm. Patients responding to saline were assigned a PC20 value that was half of the lowest concentration applied. Patients not responding to the highest concentration of methacholine or AMP were assigned a value of twice the highest concentration applied. The repeatability of sputum induction was investigated using the Bland and Altman approach (limits of agreement are expressed as \pm 2 SD of the mean of differences between two measurements, within which $95 \%$ of the differences of repeated measurements are expected to be and the mean of the difference must be close to 1) [24]. The repeatability of sputum inflammatory cells was satisfactory.

Correlations between variables were calculated with Spearman's rank correlation test. In the group of patients who successfully quit smoking, differences before and after smoking cessation were analysed using Wilcoxon's signed rank test.

\section{Results}

\section{Patient characteristics}

In total, 33 COPD patients were included into the 1-yr smoking cessation programme. PC20 methacholine was measured in 30 of 33 patients and PC20 AMP in 29 of 33 patients at baseline. Missing values were related to an FEV1 of $<1.0 \mathrm{~L}$ (the lower limit to perform a provocation test in the laboratory; table 1).

A total of 15 COPD patients successfully quit smoking (smoking cessation group). All urinary cotinine levels were negative at 2, 6 and 12 months after smoking cessation. None of the participants had used nicotine replacements.

\section{Univariate correlations of PC20 methacholine and PC20 $A M P$ with clinical and inflammatory parameters}

A highly significant positive correlation was found between both PC20 methacholine and PC20 AMP and FEV1\% pred, FEV1/VC and sGaw (table 2). There was a borderline significant negative correlation of PC20 methacholine with age $(\rho=-0.36, p=0.052)$. No significant correlations were found between PC20 methacholine or PC20 AMP and the investigated inflammatory parameters.

\section{Effect of smoking cessation on PC20 methacholine and PC20 AMP}

In 14 of 15 COPD patients, PC20 methacholine and PC20 AMP were measured both before and $1 \mathrm{yr}$ after smoking cessation. PC20 methacholine and PC20 AMP improved with smoking cessation by 1.6 and 2.1 doubling concentrations, respectively (table 1, fig. 1). More patients improved with PC20 AMP than with PC20 methacholine (11 versus 7, $\mathrm{p}=0.1$ ). Total cell concentration increased in sputum after 6 months smoking cessation from 1,160 to $3,022 \times 10^{3}$ cells $\cdot \mathrm{mL}^{-1}$ and was still increased after 12 months smoking cessation 


\begin{tabular}{|c|c|c|c|c|c|}
\hline & Total group $f$ & Baseline & After 2 months SC & After 6 months SC & After 12 months SC \\
\hline Quitters n & & 15 & 15 & 15 & 15 \\
\hline Age yrs & $55(46-67)$ & $55.6(46-63)$ & & & \\
\hline Sex M/F & $20 / 13$ & $9 / 6$ & $9 / 6$ & $9 / 6$ & $9 / 6$ \\
\hline Pack yrs & $35(15-66)$ & $34(15-66)$ & & & \\
\hline Cigarettes $\cdot$ day $^{-1}$ & $21.9(10-40)$ & $20.6(10-40)$ & & & \\
\hline FEV1 \% pred & $71(28-114)$ & $75(36-114)$ & & & 77 (42-115) \\
\hline FEV1/VC \% & $55.4(25-76)$ & $57.3(25-76)$ & & & $58.6(33-84)$ \\
\hline $\mathrm{s} G$ aw $1 \cdot \mathrm{kPa}^{-1} \cdot \mathrm{s}^{-1}$ & $0.68(0.2-1.8)$ & $0.74(0.2-1.8)$ & & & $0.66(0.28-3.43)$ \\
\hline $\mathrm{PC} 20$ AMP $\mathrm{mg} \cdot \mathrm{mL}^{-1}$ & $34.3(0.02-640)$ & $44(4.44-640)$ & & & $176(1.04-640)^{+}$ \\
\hline $\mathrm{PC} 20 \mathrm{Mch} \mathrm{mg} \cdot \mathrm{mL}^{-1}$ & $2.5(0.018-78.2)$ & $2.57(0.15-78.2)$ & & & $8.1(0.09-78.2)^{+}$ \\
\hline \multicolumn{6}{|l|}{ Sputum } \\
\hline Cell concentration $10^{3} \cdot \mathrm{mL}^{-1}$ & $1507(480-9620)$ & $1160(480-9620)$ & $2990(32-13873)$ & $3022(206-11577)^{\bullet}$ & $3314(16-12290)^{+}$ \\
\hline \multicolumn{6}{|l|}{ Eosinophils } \\
\hline $10^{3} \cdot \mathrm{mL}^{-1}$ & $17(0-130)$ & $18(0-106)$ & $7(0-111)^{\#}$ & $5(0-150)$ & $11(0-140)$ \\
\hline$\%$ & $1.5(0-4.1)$ & $1.5(0-4.0)$ & $0.7(0-2.6)^{\#}$ & $0.5(0-2.6)^{4}$ & $0.2(2-3.6)^{+}$ \\
\hline \multicolumn{6}{|l|}{ Neutrophils } \\
\hline $10^{3} \cdot \mathrm{mL}^{-1}$ & $870(240-7610)$ & $756(235-7608)$ & $2763(23-9079)$ & $1232(120-8856)^{\oplus}$ & $2879(120-11040)^{+}$ \\
\hline$\%$ & $67.3(39.1-87.3)$ & $73.8(45-86)$ & $77.8(38-97)$ & $68.3(35.5-93)$ & $78.7(31.6-89.8)^{\S}$ \\
\hline \multicolumn{6}{|l|}{ Macrophages } \\
\hline $10^{3} \cdot \mathrm{mL}^{-1}$ & $426(90-2610)$ & $407(90-2615)$ & $462(8-8268)$ & $807(9-2373)$ & $778(216-2940)$ \\
\hline$\%$ & $28.4(9.9-58.4)$ & $24.2(11.8-52.7)$ & $20.1(2.2-59.6)$ & $28(4.3-61.6)$ & $19.2(7.9-60.7)^{+}$ \\
\hline \multicolumn{6}{|l|}{ Lymphocytes } \\
\hline $10^{3} \cdot \mathrm{mL}^{-1}$ & $15(0-220)$ & $10(0-77)$ & $10(0-111)$ & $36(5-150)^{9}$ & $26(5-160)$ \\
\hline$\%$ & $0.8(0.1-4.6)$ & $0.8(0.1-1.1)$ & $0.8(0.1-1.3$ & $1.3(0.5-2.6)^{\top}$ & $0.8(0.1-3.0)$ \\
\hline \multicolumn{6}{|l|}{ Epithelial cells } \\
\hline $10^{3} \cdot \mathrm{mL}^{-1}$ & $8(0-110)$ & $7(0-60)$ & $0.2(0-83)$ & $34(0-751)^{\uparrow}$ & $22(0-98)^{+}$ \\
\hline$\%$ & $0.5(0-11)$ & $0.3(0-2.1)$ & $0.1(0-0.8)^{\#}$ & $0.8(0-13.3)$ & $0.55(0-6)$ \\
\hline
\end{tabular}

Data are presented as $\mathrm{n}$ and median (range), except for age, forced expiratory volume in one second (FEV1) and FEV1/vital capacity (VC) in mean (range), and for provocative concentration causing a 20\% fall in FEV1 (PC20) of adenosine-5'-monophosphate (AMP) and PC20 of methacholine (Mch) in geometric mean (range). M: male; F: female; sGaw: airway conductance; SC: smoking cessation. \#: p $<0.05$ before SC versus 2 months after SC; ๆ: $\mathrm{p}<0.05$ before $\mathrm{SC}$ versus 6 months after SC; ${ }^{+}: \mathrm{p}<0.05$ before SC versus 12 months after SC; $;^{\S}$ : $\mathrm{p}=0.056$ before SC versus after 12 months SC; ${ }^{f}$ : $=33$.

$\left(3,314 \times 10^{3}\right.$ cells $\left.\cdot \mathrm{mL}^{-1}\right)$. The number of epithelial cells showed the same pattern: from 7 to 34 , and to $22 \times 10^{3}$ cells $\cdot \mathrm{mL}^{-1}$ at the same time points, respectively. The number of neutrophils increased after 6 months smoking cessation from 756 to $1,232 \times 10^{3}$ cells $\cdot \mathrm{mL}^{-1}$ and increased even more after 12

Table 2.-Spearman's rank correlations ( $\rho)$ of clinical and inflammatory parameters with provocative concentration causing a $20 \%$ fall in forced expiratory volume in one second (PC20) of methacholine (Mch) and $\mathrm{PC}_{20}$ of adenosine-5'-monophosphate (AMP)

\begin{tabular}{|c|c|c|c|c|}
\hline & \multicolumn{2}{|c|}{ PC20 Mch } & \multicolumn{2}{|c|}{ PC20 AMP } \\
\hline & $\rho$ & $\mathrm{p}$-value & $\rho$ & $\mathrm{p}$-value \\
\hline Subjects n & \multicolumn{2}{|c|}{30} & \multicolumn{2}{|c|}{29} \\
\hline Age & -0.36 & 0.052 & -0.30 & 0.12 \\
\hline Sex & 0.016 & 0.93 & 0.089 & 0.65 \\
\hline Pack yrs & -0.097 & 0.61 & -0.19 & 0.34 \\
\hline Cigarettes $\cdot$ day $^{-1}$ & 0.26 & 0.17 & 0.28 & 0.14 \\
\hline FEV1 \% pred & 0.75 & 0.00 & 0.58 & 0.001 \\
\hline $\mathrm{FEV} / / \mathrm{VC} \%$ & 0.82 & 0.00 & 0.87 & 0.00 \\
\hline $\mathrm{s} G$ aw $1 \cdot \mathrm{kPa}^{-1} \cdot \mathrm{s}^{-1}$ & 0.70 & 0.00 & 0.69 & 0.00 \\
\hline \multicolumn{5}{|l|}{ Sputum $10^{3} \cdot \mathrm{mL}^{-1}$} \\
\hline Cell concentration & 0.086 & 0.65 & 0.080 & 0.68 \\
\hline Eosinophils & -0.32 & 0.085 & -0.21 & 0.28 \\
\hline Neutrophils & 0.009 & 0.96 & -0.032 & 0.87 \\
\hline Macrophages & 0.26 & 0.16 & 0.23 & 0.22 \\
\hline Lymphocytes & -0.071 & 0.71 & -0.06 & 0.75 \\
\hline Epithelial cells & -0.25 & 0.18 & -0.18 & 0.36 \\
\hline
\end{tabular}

FEV1: forced expiratory volume in one second; VC: vital capacity; sGaw: airway conductance. months smoking cessation to $2,879 \times 10^{3}$ cells $\cdot \mathrm{mL}^{-1}$ (table 1 , fig. 2).

No significant correlations were found between changes in PC20 AMP or in PC20 methacholine with smoking cessation and changes in variables of lung function or sputum inflammation (table 3).

\section{Discussion}

This study of 33 smoking COPD patients showed that PC20 methacholine and PC20 AMP were associated with prechallenge lung function parameters (FEV1, FEV1/VC and $\mathrm{s} G \mathrm{aw}$ ); however, total and differential cell counts in sputum did not correlate with the severity of airway responsiveness to either provocative stimulus. An important observation of this longitudinal study is that PC20 methacholine improved with 1.6 doubling concentrations and PC20 AMP with 2.1 doubling concentrations after a 1-yr smoking cessation. These improvements in AHR were not associated with improvements in sputum total and differential cell counts.

WISE et al. [14] recently showed that AHR to methacholine deteriorated over a 5-yr period in patients with COPD, which was more pronounced in persistent smokers than in quitters. This suggests that smoking cessation prevents further deterioration in AHR. In contrast, the current study shows an improvement in AHR to methacholine after a 1-yr smoking cessation. The main differences between this study and the Lung Health Study are the smoking cessation period and the number of subjects. It may well be that after a 1-yr smoking cessation AHR improves, since it has been shown that: 1) during the first year of smoking cessation FEV1 may improve; and 2) that changes in AHR in COPD are closely 


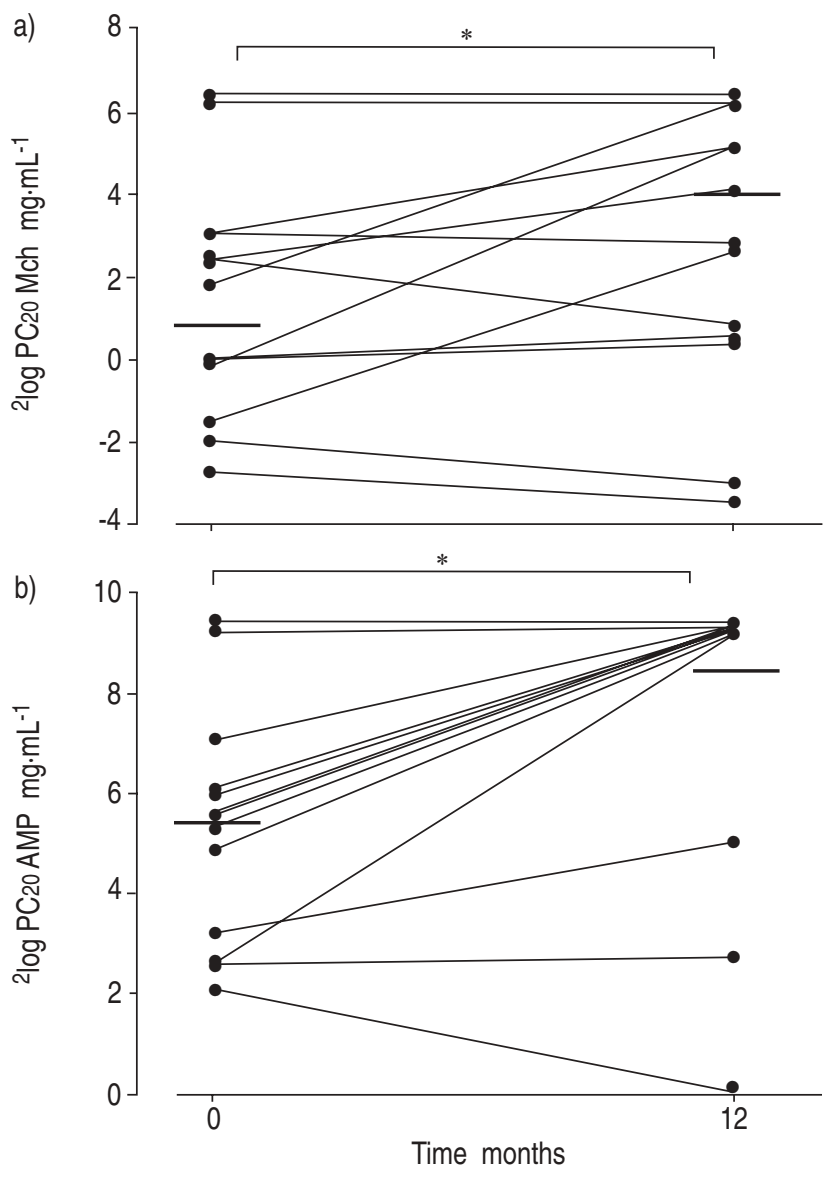

Fig. 1. - a) Provocative concentration causing a $20 \%$ fall in forced expiratory volume in one second ( $\mathrm{PC}_{20}$ ) of methacholine (Mch) and b) $\mathrm{PC}_{20}$ of adenosine- $5^{\prime}$-monophosphate (AMP) before and after 12 months smoking cessation in patients with chronic obstructive pulmonary disease. Horizontal bars represent median values. ${ }^{2} \log$ : base-2 logarithm. *: $\mathrm{p}<0.05$.

related to changes in FEV1 [9, 14, 25]. After a 5-yr smoking cessation, this positive effect on AHR may have been

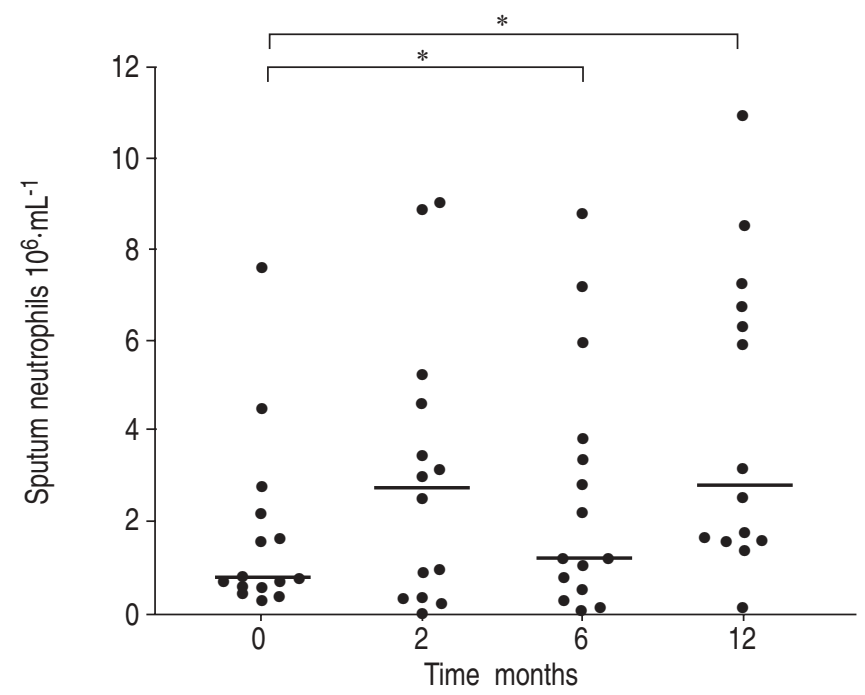

Fig. 2. - Sputum neutrophils $\left(10^{3} \cdot \mathrm{mL}^{-1}\right)$ before and after 2,6 and 12 months smoking cessation in patients with chronic obstructive pulmonary disease. Horizontal bars represent median values. *: $\mathrm{p}<0.05$.
Table 3. - Spearman's correlations $(\rho)$ of changes $(\Delta)$ in clinical and inflammatory parameters with $\Delta$ in provocative concentration causing a $20 \%$ fall in forced expiratory volume in one second (PC20) of methacholine (Mch) or $\mathrm{PC}_{20}$ of adenosine-5'-monophosphate (AMP) during a 1-yr smoking cessation

\begin{tabular}{|c|c|c|c|c|}
\hline & \multicolumn{2}{|c|}{$\Delta \mathrm{PC} 20 \mathrm{Mch}$} & \multicolumn{2}{|c|}{$\triangle \mathrm{PC} 20 \mathrm{AMP}$} \\
\hline & $\rho$ & $\mathrm{p}$-value & $\rho$ & p-value \\
\hline$\triangle \mathrm{FEV} 1 \%$ pred & 0.075 & 0.80 & 0.18 & 0.53 \\
\hline$\Delta \mathrm{FEV}_{1} / \mathrm{VC}^{\circ} \%$ & -0.106 & 0.72 & 0.06 & 0.85 \\
\hline$\Delta \mathrm{s} G$ aw $1 \cdot \mathrm{kPa}^{-1} \cdot \mathrm{s}^{-1}$ & 0.004 & 0.99 & 0.077 & 0.79 \\
\hline \multicolumn{5}{|l|}{ Sputum $10^{3} \cdot \mathrm{mL}^{-1}$} \\
\hline$\Delta$ Cell concentration & -0.32 & 0.27 & 0.044 & 0.8 \\
\hline$\Delta$ Eosinophils & -0.036 & 0.91 & -0.36 & 0.23 \\
\hline$\Delta$ Neutrophils & 0.18 & 0.56 & -0.008 & 0.98 \\
\hline$\Delta$ Macrophages & -0.15 & 0.64 & 0.083 & 0.79 \\
\hline$\Delta$ Lymphocytes & 0.34 & 0.26 & 0.28 & 0.36 \\
\hline$\Delta$ Epithelial cells & -0.11 & 0.71 & -0.14 & 0.65 \\
\hline
\end{tabular}

FEV1: forced expiratory volume in one second; VC: vital capacity; sGaw: airway conductance.

overruled by the deterioration in AHR due to ageing in COPD patients [26].

AMP responsiveness has been reported to be more severe in smoking than in exsmoking COPD patients [13]. The latter is compatible with the current authors' longitudinal study, showing that AMP responsiveness improves significantly with 2.1 doubling concentrations after a 1-yr persistent smoking cessation and it improves in virtually all of the COPD patients. A remarkable observation is that improvements in hyperresponsiveness were not associated with changes in sputum inflammatory cell counts. Thus, at least in COPD, changes in hyperresponsiveness to an indirect and direct airway challenge are not due to changes in actual airway inflammation as assessed with induced sputum.

The observed improvement in hyperresponsiveness after smoking cessation may well have been caused by other factors. For instance, geometric changes in the airways may be important, like a decrease in mucus hypersecretion and airway smooth muscle hypertrophy. Mucus hypersecretion could have diminished within $1 \mathrm{yr}$, since goblet cell hyperplasia in the central airways is lower in exsmokers than in smokers with mild COPD [27]. This is also compatible with the observed improvements in chronic cough and sputum production when patients with COPD quit smoking $[25,28]$. However, lung function (FEV1 \% pred, FEV1/VC and sGaw) did not improve significantly after a 1 -yr smoking cessation in this study. This may be due to irreversible parenchymal and peribronchial changes. Nevertheless, some patients may improve their FEV1 after smoking cessation, since the Lung Health Study [2] found a small improvement in FEV1 of $+57 \mathrm{~mL}$ after a 1-yr smoking cessation. However, the Lung Health Study investigated 5,887 patients against 14 in the current study. Thus, this study may have had lack of power to reveal this small change.

Another factor contributing to the improvement in AHR may be the interaction between smoking substances and sensory nerve endings in the airway wall. Smoking can stimulate sensory nerve endings in the airway wall, which in turn release acetylcholine and tachykinins [29, 30]. These tachykinins can cause airway smooth muscle contraction and, additionally, they can enhance AHR by an increase of airway wall oedema, mucus hypersecretion, recruitment of inflammatory cells and possibly smooth muscle hypertrophy resulting from chronic stimulation [31]. When a patient quits smoking the release of tachykinins will diminish and AHR 
may improve. Further studies have to explore the role of tachykinins in AHR after smoking cessation. A provocation test with bradykinine is an attractive option, since bradykinine is supposed to directly stimulate sensory nerve endings [29].

AMP acts mainly via the release of mast cell mediators. The observed improvement in AHR to the indirect stimulus AMP after smoking cessation may result from a decreased number or activation state of mast cells in the airway wall. Indeed, PESCI et al. [32] showed that the number of mast cells in bronchial epithelium, the lamina propria and bronchoalveolar lavage tended be lower in bronchial biopsies of exsmokers with COPD than in smokers with COPD. Mast cell numbers in sputum are far too low for useful determination, thus any evaluation of a possible contribution was impossible in the current study.

Unfortunately, the beneficial effects of smoking cessation in the COPD patients could not be compared with observations in individuals who were unable to quit smoking, since the medical ethics committee decided it was unethical to re-assess individuals who relapsed after a smoking cessation attempt. However, it is not likely that the observed improvement in hyperresponsiveness is a spurious finding, since previous studies have reported that hyperresponsiveness to methacholine and histamine deteriorated in smokers with COPD who continued to smoke for 5 and 2 yrs, respectively $[14,26]$. RENKEMA et al. [26] even showed that this was independent of the use of inhaled or oral corticosteroids. In addition, LIM et al. [33] showed that AHR to carbachol in "healthy" smokers deteriorated, whereas AHR did not deteriorate in exsmokers. Thus, it would have been unlikely to expect that a group of COPD patients who continued smoking would have shown an improvement in AHR.

Consistent with observations in the Lung Health Study [2], the current authors' cross-sectional data showed that PC20 methacholine and PC20 AMP in smokers with COPD were positively associated with FEV1\% pred, FEV1/VC and sGaw.

Intuitively, it would be expected that the degree of inflammation is associated with the severity of hyperresponsiveness in COPD patients. Indeed, other studies showed that more severe methacholine responsiveness was related to more inflammation in lung tissue $[6,17]$. In addition, AMP responsiveness was reported to be associated with an increase in percentage of sputum eosinophils and in the number of CD8+ cells in bronchial biopsies from exsmokers with COPD [18]. In this study, a cross-sectional significant association between inflammation in sputum and both direct and indirect AHR was not found. On the contrary, the number of sputum cells and especially neutrophils and epithelial cells increased 6 and 12 months after smoking cessation, whereas PC20 methacholine and AMP improved. Indeed, the current authors found some negative correlation coefficients between changes in PC20 values and changes in sputum cell counts. This observation may indicate that sputum is not the right representative compartment to assess an influence of inflammation on AHR in COPD. Results of two previous studies comparing bronchoalveolar lavage, sputum and airway wall biopsies have already suggested that sputum inflammatory assessments are not representative for inflammation throughout the lung $[22,34]$. Yet another interpretation of the current authors' findings is that the increase in neutrophils, already seen after 6 months smoking cessation, is just a reflection of a decrease in neutrophils in the airway wall and, thus, sputum could be regarded as a "rubbish bin" in COPD. This then would suggest improvement of neutrophilic inflammation in the airway wall and/or lung tissue. Further studies using airway wall biopsies in conjunction with smoking cessation have to determine whether this is indeed the case.
Despite the lack of a control group, the current authors are confident that the changes in sputum cells are due to smoking cessation. Sputum induction was only performed in stable patients. BEEH et al. [35] have shown that repeatability of sputum samples in COPD patients was satisfactory using the intraclass coefficient of variation. In addition, the current authors' results on sputum repeatability using the BLAND and ALTMAN [24] approach were satisfactory; for example, for neutrophil numbers the mean of difference was -1.2 and $>95 \%$ of the differences of repeated measurements was within the range of \pm 2 times the standard deviation $(\mathrm{SD}=2.7)$.

In summary, the cross-sectional analysis in smokers with COPD showed that AHR to both methacholine and AMP is associated with a lower lung function, yet with increased inflammatory cells in sputum. Studies using bronchial biopsies may give a better insight into this relationship.

Smoking cessation remains the most beneficial therapy for chronic obstructive pulmonary disease patients, given its beneficial effects on respiratory symptoms and decline in forced expiratory volume in one second. This study shows that a 1-yr smoking cessation improves airway hyperresponsiveness to both direct and indirect stimuli in chronic obstructive pulmonary disease. This improvement was, however, not related to changes in lung function or sputum total and differential cell counts. The latter even increased after smoking cessation, which may simply indicate that sputum is not the right compartment to assess inflammation in relation to airway hyperresponsiveness in chronic obstructive pulmonary disease. The observed improvement in airway hyperresponsiveness might result either from a reduced stimulation of irritant receptors, a decrease in mucus hypersecretion, or changes in cells in the airway wall and/or lung tissue not yet reflected by induced sputum.

Acknowledgements. The authors would like to thank H.M. Boezen for statistical advice.

\section{References}

1. Postma DS, Kerstjens HA. Characteristics of airway hyperresponsiveness in asthma and chronic obstructive pulmonary disease. Am J Respir Crit Care Med 1998; 158: S187-S192.

2. Tashkin DP, Altose MD, Bleecker ER, et al. The lung health study: airway responsiveness to inhaled methacholine in smokers with mild to moderate airflow limitation. The Lung Health Study Research Group. Am Rev Respir Dis 1992; 145: 301-310.

3. Yan K, Salome CM, Woolcock AJ. Prevalence and nature of bronchial hyperresponsiveness in subjects with chronic obstructive pulmonary disease. Am Rev Respir Dis 1985; 132: 25-29.

4. Nagai A, Thurlbeck WM, Konno K. Responsiveness and variability of airflow obstruction in chronic obstructive pulmonary disease. Clinicopathologic correlative studies. Am J Respir Crit Care Med 1995; 151: 635-639.

5. Koyama H, Nishimura K, Ikeda A, Sakai N, Mishima M, Izumi $\mathrm{T}$. Influence of baseline airway calibre and pulmonary emphysema on bronchial responsiveness in patients with chronic obstructive pulmonary disease. Respir Med 1996; 90: 323-328.

6. Finkelstein R, Ma HD, Ghezzo H, Whittaker K, Fraser RS, Cosio MG. Morphometry of small airways in smokers and its relationship to emphysema type and hyperresponsiveness. Am J Respir Crit Care Med 1995; 152: 267-276.

7. Ramsdale EH, Morris MM, Roberts RS, Hargreave FE. Bronchial responsiveness to methacholine in chronic 
bronchitis: relationship to airflow obstruction and cold air responsiveness. Thorax 1984; 39: 912-918.

8. Wiggs BR, Bosken C, Pare PD, James A, Hogg JC. A model of airway narrowing in asthma and in chronic obstructive pulmonary disease. Am Rev Respir Dis 1992; 145: 1251-1258.

9. Anthonisen NR, Connett JE, Kiley JP, et al. Effects of smoking intervention and the use of an inhaled anticholinergic bronchodilator on the rate of decline of FEV1. The Lung Health Study. JAMA 1994; 272: 1497-1505.

10. Fletcher $\mathrm{C}$, Peto R. The natural history of chronic airflow obstruction. Br Med J 1977; 1: 1645-1648.

11. Sterk PJ, Fabbri LM, Quanjer PH, et al. Airway responsiveness. Standardized challenge testing with pharmacological, physical and sensitizing stimuli in adults. Report Working Party Standardization of Lung Function Tests, European Community for Steel and Coal. Official Statement of the European Respiratory Society. Eur Respir J 1993; 16: 53-83.

12. Postma DS, Renkema TE, Noordhoek JA, Faber H, Sluiter HJ, Kauffman H. Association between nonspecific bronchial hyperreactivity and superoxide anion production by polymorphonuclear leukocytes in chronic air-flow obstruction. Am Rev Respir Dis 1988; 137: 57-61.

13. Oosterhoff Y, de Jong JW, Jansen MA, Koeter GH, Postma DS. Airway responsiveness to adenosine 5'-monophosphate in chronic obstructive pulmonary disease is determined by smoking. Am Rev Respir Dis 1993; 147: 553-558.

14. Wise RA, Kanner RE, Lindgren $\mathrm{P}$, et al. The effect of smoking intervention and an inhaled bronchodilator on airways reactivity in COPD: the Lung Health Study. Chest 2003; 124: 449-458.

15. van den Berge M, Meijer RJ, Kerstjens HA, et al. $\mathrm{PC}(20)$ adenosine $5^{\prime}$-monophosphate is more closely associated with airway inflammation in asthma than PC(20) methacholine. Am J Respir Crit Care Med 2001; 163: 1546-1550.

16. van den Berge M, Kerstjens HA, Meijer RJ, et al. Corticosteroid-induced improvement in the PC20 of adenosine monophosphate is more closely associated with reduction in airway inflammation than improvement in the PC20 of methacholine. Am J Respir Crit Care Med 2001; 164: $1127-1132$.

17. Mullen JB, Wiggs BR, Wright JL, Hogg JC, Pare PD. Nonspecific airway reactivity in cigarette smokers. Relationship to airway pathology and baseline lung function. Am Rev Respir Dis 1986; 133: 120-125.

18. Rutgers SR, Timens W, Tzanakis $\mathrm{N}$, et al. Airway inflammation and hyperresponsiveness to adenosine $5^{\prime}$ monophosphate in chronic obstructive pulmonary disease. Clin Exp Allergy 2000; 30: 657-662.

19. Siafakas NM, Vermeire P, Pride NB, et al. Optimal assessment and management of chronic obstructive pulmonary disease (COPD). Eur Respir J 1995; 8: 1398-1420.

20. Quanjer PH, Tammeling GJ, Cotes JE, Pedersen OF, Peslin R, Yernault JC. Lung volumes and forced ventilatory flows. Eur Respir J Suppl 1993; 16: 5-40.

21. Cockcroft DW, Killian DN, Mellon JJ, Hargreave FE.
Bronchial reactivity to inhaled histamine: a method and clinical survey. Clin Allergy 1977; 7: 235-243.

22. Rutgers SR, Timens W, Kaufmann HF, van der Mark TW, Koeter GH, Postma DS. Comparison of induced sputum with bronchial wash, bronchoalveolar lavage and bronchial biopsies in COPD. Eur Respir J 2000; 15: 109-115.

23. Fahy JV, Liu J, Wong H, Boushey HA. Cellular and biochemical analysis of induced sputum from asthmatic and from healthy subjects. Am Rev Respir Dis 1993; 147: 11261131.

24. Bland JM, Altman DG. Statistical methods for assessing agreement between two methods of clinical measurement. Lancet 1986; 1: 307-310.

25. Kanner RE, Connett JE, Williams DE, Buist AS. Effects of randomized assignment to a smoking cessation intervention and changes in smoking habits on respiratory symptoms in smokers with early chronic obstructive pulmonary disease: the Lung Health Study. Am J Med 1999; 106: 410-416.

26. Renkema TE, Kerstjens HA, Schouten JP, Vonk JM, Koeter GH, Postma DS. The importance of serum IgE for level and longitudinal change in airways hyperresponsiveness in COPD. Clin Exp Allergy 1998; 28: 1210-1218.

27. Wright JL, Lawson LM, Pare PD, Wiggs BJ, Kennedy S, Hogg JC. Morphology of peripheral airways in current smokers and ex-smokers. Am Rev Respir Dis 1983; 127: 474 477.

28. Pride NB. Smoking cessation: effects on symptoms, spirometry and future trends in COPD. Thorax 2001; 56: Suppl. 2, II7-II10.

29. Barnes PJ. Neurogenic inflammation in airways. Int Arch Allergy Appl Immunol 1991; 94: 303-309.

30. Hong JL, Rodger IW, Lee LY. Cigarette smoke-induced bronchoconstriction: cholinergic mechanisms, tachykinins, and cyclooxygenase products. J Appl Physiol 1995; 78: 22602266.

31. Van Schoor J, Joos GF, Pauwels RA. Indirect bronchial hyperresponsiveness in asthma: mechanisms, pharmacology and implications for clinical research. Eur Respir J 2000; 16 : 514-533.

32. Pesci A, Rossi GA, Bertorelli G, Aufiero A, Zanon P, Olivieri D. Mast cells in the airway lumen and bronchial mucosa of patients with chronic bronchitis. Am J Respir Crit Care Med 1994; 149: 1311-1316.

33. Lim TK, Taylor RG, Watson A, Joyce H, Pride NB. Changes in bronchial responsiveness to inhaled histamine over four years in middle aged male smokers and exsmokers. Thorax 1988; 43: 599-604.

34. Maestrelli P, Saetta M, Di Stefano A, et al. Comparison of leukocyte counts in sputum, bronchial biopsies, and bronchoalveolar lavage. Am J Respir Crit Care Med 1995; 152: 1926-1931.

35. Beeh KM, Beier J, Kornmann O, Mander A, Buhl R. Longterm repeatability of induced sputum cells and inflammatory markers in stable, moderately severe COPD. Chest 2003; 123 : 778-783. 